\title{
¿FORMACIÓN/DEFORMACIÓN DEL MAESTRO? REFLEXIONES Y LAMENTOS DE DOS PROFESORES INCRÉDULOS
}

\section{Teacher education/miseducation? Thoughts and laments of two sceptic theachers}

\author{
Alejandro Ávila FernÁNDEZ \\ Universidad de Sevilla \\ Correo-e: aavila@us.es \\ Juan A. Holgado Barroso \\ Universidad de Sevilla \\ Correo-e: jholgado@cica.es
}

Recepción: 2 de diciembre de 20I4. Envío a informantes: 7 de diciembre de 2014.

Fecha de aceptación definitiva: 4 de febrero de 2015

Resumen: La base de este trabajo consiste en un estudio analítico, dentro de lo posible, de la formación del maestro-a desde tres elementos fundamentales e interdependientes cuales son el institucional, el curricular y el legislativo. La historia es nuestro principal testigo y la realidad actual corrobora vivencias pasadas y presentes. Sin caer en pesimismos ni derrotismos tratamos de dejar bien reflejada que la formación del maestro-a es a la vez, paradójicamente, deformación y que ambos paradigmas han convivido y conviven en la actualidad.

PALABRAS ClAVE: maestro; maestra; formación; deformación; historia; actualidad.

ABSTRACT: This work is based on an analytical study of the teachers' education from three fundamental and interdependent points of view: the institutional, the curricular and the legislative one. History is our main witness and present reality corroborates past and present experiences. Without falling into pessimism or defeatism, we try to reflect properly that teacher education is at the same time and, paradoxically, miseducation, and that both paradigms coexist today and have done so/coexisted in the past.

KEY WORDs: teacher; education; miseducation; history; present. 
O PARADÓJICO Y PARADIGMÁTICO A LA VEZ de este título es que sin querer ser pretencioso ni siquiera «snob» y, por supuesto sin inmodestia aparte, es de una realidad meridiana y de una verdad sin desmayo. No lo digo yo, desde luego no sólo yo. La historia nos respalda; y si lo hace es porque da cuenta de la experiencia. No quiero ser intérprete de la historia en sentido absoluto, sólo quiero reflejar la «espada de Damocles» con la que el magisterio en España ha vivido/sigue viviendo a lo largo ya de varios siglos. La mejor forma de reconocer este aserto de título es conocer el trayecto seguido para conseguir una formación /deformación de los enseñantes primarios.

Voy a intentar proyectar imágenes a modo de flashes para que entendamos la necesidad de la educación, de la escuela primaria y, por supuesto, del maestro y lo que éste representaba/representa. Al mismo tiempo quiero dejar bien patente que este recorrido que ahora voy a iniciar está planteado desde sus orígenes, es decir, desde mediados del siglo xix como momento de mayor tensión y de reivindicaciones constantes; adentrándome también en el siglo xx donde muchos de los problemas al no hallarse siquiera en vías de solución van a estar presentes durante casi todo el siglo y, por supuesto, continuar con un análisis, todavía no demasiado exhaustivo, pero sí significativo de lo que actualmente se baraja en nuestro siglo xxi. Por tanto, aunque toda la temática que les presento tenga unas raíces bien asentadas en la historia tómenlas además como de la más reciente actualidad.

La base de este trabajo consiste en el estudio analítico de la formación del maestro-a desde tres elementos fundamentales e interdependientes, cuales son el institucional, el curricular y el legislativo -que voy a seguir llamando "normalistas» como una especie de brindis a la historia-, entregándome a ellos con vistas a preguntarnos sobre la capacitación del magisterio en la historia reciente, a través de los planes de estudios, de acuerdo a una serie de condicionantes normativos considerando que estos tres elementos son los puntos de apoyo, la base para poder entender este recorrido de forma más solvente, conocimiento de una historia, en algunos casos de una «histeria» indesmayable durante los siglos XIX, XX y XXI en la formación del magisterio, que en sus momentos más acertados puede catalogarse de esplendorosa y el resto de miserable. Las fechas iniciales parten de I834 con la creación de las Escuelas Normales -Centros de formación del magisteriohasta 1970 -que es cuando se inicia su andadura universitaria-, para terminar en el año 2007 con las nuevas titulaciones. Vamos a ir recorriéndola lo más brevemente posible, intentando interpretar la documentación puesta a nuestro alcance y someterla a nuestra más neutral -objetiva, sin desterrar la subjetiva- y elemental -por qué no- capacidad de estudio y razonamiento.

La pretensión es simple, dar cuenta de unos hechos, de un tiempo y de un espacio que hemos manejado hasta la saciedad durante los procesos de investigaciones anteriores -y actuales-, y nos han posibilitado las pautas para llegar a conocimientos aceptables sobre la formación de los maestros y maestras. Es indudable que hemos conseguido resultados, no soluciones, ante una ingente cantidad de contenidos y actuaciones, tanto heurísticas como hermenéuticas; elaboraciones críticas sobre el tema, detectando irreversiblemente en muchos casos cómo el Estado con su atosigamiento legislativo/curricular planificado al milímetro, 
¿FORMACIÓN/DEFORMACIÓN DEL MAESTRO?

REFLEXIONES Y LAMENTOS DE DOS PROFESORES INCRÉDULOS

ALEJANDRO ÁVILA FERNÁNDEZ Y JUAN A. HOLGADO BARROSO

aunque demasiado ineficaz en la mayoría de los casos, agobió, asfixió y sigue haciéndolo, la actuación profesional de un gremio desde sus inicios denostado.

La formación del maestro/a, a nuestro entender, está basada en la exposición de un conglomerado de distintas corrientes que han propuesto nuevas formas críticas de entender su formación, desde varios ángulos: la cultura, la educación -y dentro de ésta el sistema educativo-, la estructura social y el poder político, desde la pedagogía crítica de Giroux hasta la historia social y política y las sociologías crítico-históricas españolas con Carlos Lerena a la cabeza (sin olvidar a Julia Valera o Félix Ortega, entre otros), pasando por el método genealógico de Foucault. Desde estos enfoques entendemos los centros de formación del magisterio primario -Escuelas Normales, Escuelas de Magisterio, de Formación del Profesorado de EGB, hasta el de Facultades de Educación en sus distintas denominaciones actuales, etc.-, como instituciones históricas y culturales que siempre encarnaron y encarnan intereses políticos e ideológicos fuera de los cuales la cultura dominante fabrica sus certezas hegemónicas; pero también son lugares donde grupos dominantes y subordinados se definen y coaccionan mutuamente a través de una lucha y un intercambio ininterrumpidos en respuesta a las condiciones socioculturales que arrastran en sí mismas las prácticas institucionales, textuales y vivenciales definidoras de la cultura escolar y de la experiencia de profesores y estudiantes. Son, en cualquier caso, todo menos realidades ideológicas inocentes, y tampoco se limitan a reproducir las relaciones sociales y los intereses dominantes. Al mismo tiempo, ejercen de hecho formas de regulación política y moral íntimamente ligadas a tecnologías de poder que reproducen asimetrías en las habilidades de los individuos y los grupos para definir y tomar conciencia de sus necesidades. Más específicamente, las Escuelas Normales fijan las condiciones bajo las cuales otros viven, oponen resistencia, afirman y participan en la construcción de sus propias identidades y subjetividades.

Dentro de estas instituciones tiene lugar un proceso cultural, político e ideológico centrado en el plan de estudios normalista, concebido formalmente como el conjunto ordenado de enseñanzas y prácticas, que han de cursarse en las mismas para la obtención del título de maestro/a de primera enseñanza; se presenta como la columna vertebral de la formación del magisterio. Elaborado por el gobierno de turno, con o sin participación de los sectores educativos implicados (fundamentalmente el profesorado), recoge todos los componentes formativos desde la propia finalidad institucional hasta la estructuración temporal de disciplinas y actividades. Por lo tanto, su elaboración no es un proceso técnico-administrativo neutro, sino que entran en juego factores sociales, políticos, ideológicos, culturales y educativos.

El plan de estudios, en tanto proyecto educativo, se ha configurado como una respuesta a dichas exigencias, cuyo punto de partida debió ser, debe ser, la función de la escuela y del maestro. En una institución adoctrinadora, uniformadora, autoritaria, reproductora y aislacionista, las competencias docentes son bien sencillas: mantener el orden y transmitir conocimientos, condicionadas por una finalidad ideológica evidente. De ahí que su formación no presente grandes exigencias y esfuerzos, manifestándose en un plan meramente instructivo, reducido -temporal y materialmente- a la adquisición/ampliación de los contenidos propios de la 
enseñanza primaria y a la reproducción de valores, actitudes y hábitos (acciones propias de las profesiones ideológicas). Como mantiene Carlos Lerena, para ejercer como maestro se considera imprescindible que los candidatos estén en condiciones de dar respuestas en las cuestiones relativas al ser, no al saber, mediante rutinas prácticas y altas dosis de moralidad, alrededor de un vacío intelectual profundo. Cuando, desde experiencias y proyectos renovadores, se exige una escuela transformadora, educadora, creativa e interrelacionada con su entorno, entonces se transforma y aumenta la labor docente. Su formación se prolonga e intensifica: mayor selección y preparación, ampliación e incorporación de nuevos conocimientos, atención preferente a los aspectos profesionales, etc. En definitiva, del maestro instructor pasamos al maestro educador.

Los distintos planes implantados en la formación del magisterio primario español serán el medio por el cual se pone en evidencia las distancias entre las ideas y la realidad, entre la instrucción y la educación, fuertemente condicionadas por las limitaciones económicas, al menos esta fue una de las luchas más ignominiosas que puso tierra por medio para arreglar el problema del magisterio: su condición o estabilidad económica, muy denostada a lo largo de la historia o aplíquese el «pasas más hambre que un maestro de escuela», porque el verdadero problema siempre estuvo centrado en el conflicto que supuso la exigencia de una capacitación profesional larga y costosa y la ridícula y miserable retribución que tradicionalmente ha recibido el maestro. También por los postulados políticos e ideológicos, porque se trata de formar al futuro maestro para ser, en palabras de Gramsci, un empleado del grupo dominante para el ejercicio de las funciones subalternas de la hegemonía social y del gobierno político, es decir, del consenso espontáneo que las grandes masas de la población dan a la dirección impuesta -entre otros medios por la instrucción pública- a la vida social por el grupo fundamental dominante y del aparato de coerción estatal que asegura legalmente la disciplina de aquellos grupos que no consienten. $\mathrm{Y}$ también, en definitiva, el aprendiz de maestro/a se formará en la función de inculcar/imponer una determinada cultura:

Con esto, y de cara a la población obrera y campesina, el maestro venía a ser una especie de doctor Tirteafuera, representante de los hábitos correctos, esto es, corregidos, encargado de mostrar la línea de demarcación entre cultura dominante y culturas dominadas. Objeto de devoción, y al mismo tiempo de ironía, el maestro desempeña funciones de super ego: encarna el catálogo de prohibiciones impuesto al conjunto dominado en el campo de la cultura ${ }^{1}$.

Entre los componentes curriculares están las asignaturas, reguladas por los diferentes planes de estudios según los grados y cursos, que constituyen el punto de referencia inicial de la acción formativa y más concretamente del trabajo docente, representando la sistematización y prescripción previa del proceso enseñanzaaprendizaje, cuya elaboración compete a las autoridades ministeriales, siendo un índice o relación de todos los temas integrantes de las diferentes materias además de donde se expresan los distintos conocimientos a impartir detallados en unidades de contenido más específicas. Junto a estos componentes, la actividad legisladora se

Lerena Aleson, C.: Escuela, ideología y clases sociales en España, Barcelona, Ariel, 1976, p. 192. 
¿FORMACIÓN/DEFORMACIÓN DEL MAESTRO?

REFLEXIONES Y LAMENTOS DE DOS PROFESORES INCRÉDULOS

ALEJANDRO ÁVILA FERNÁNDEZ Y JUAN A. HOLGADO BARROSO

detendrá, y muy especialmente a partir de la aparición de cada plan, en publicar una relación normativa de conmutaciones o convalidaciones de asignaturas correspondientes a anteriores planes o a otras cursadas en diferentes modalidades formativas. Las disciplinas, con sus correspondientes programas, serán un reflejo directo de las concepciones sociales, políticas, culturales y educativas imperantes en cada momento histórico acerca de lo que debe ser la formación del maestro.

Además, dentro de una enseñanza intelectualista se materializará un número determinado de lecciones sobre cada asignatura a transmitir por el docente y aprender por el alumno. La atención se fija en el cuánto se puede enseñar, olvidándose el cómo desarrollar los conocimientos, habilidades, experiencias, etc., todos ellos respondiendo a los propósitos intervencionistas, uniformantes y normalizadores de la enseñanza por parte de los Estados, que en nuestro caso pretenden ser un instrumento de poder y control puesto en marcha por el modelo liberal para acaparar progresivamente la formación del maestro, caracterizándose por los siguientes rasgos: su confección responde a dichas finalidades y no a la realidad escolar; son en general demasiados extensos, de ahí que su desarrollo esté limitado por las posibilidades humanas y materiales de cada contexto, y aparecen como una norma o guía general exigida por el Estado, facultando para la aplicación docente posterior. Por su parte, el programa será la expresión previa, ordenada y detallada de los conocimientos teóricos y prácticos que debe impartir el profesor, donde podría reflejar una serie de observaciones, notas, comparaciones, experimentos, materiales, etc. Pero, dadas las características y condicionantes de la enseñanza española, difícilmente se podrán poner en marcha unos programas acordes con las necesidades e intereses de las instituciones.

Por otra parte, desde que el alumno/a ingresa en las instituciones docentes -normalistas en nuestro caso- hasta la finalización de sus estudios, se verá sometido a una serie de pruebas encaminadas a comprobar y valorar el nivel de conocimientos adquiridos. Además ofrecerán un instrumento real y visible de control, no sólo referido al aprendizaje, sino a la propia actividad escolar en cuanto indicador efectivo del proceso instructivo. Los estudios en el campo de la genealogía y sus aportaciones a la investigación educativa han demostrado que la función examinadora va más allá:

El examen combina las técnicas de la jerarquía que vigila y las de la sanción que normaliza. Es una mirada normalizadora, una vigilancia que permite calificar, clasificar y castigar. Establece sobre los individuos una visibilidad a través de la cual se los diferencia y se los sanciona. A esto se debe que, en todos los dispositivos de disciplina, el examen se halle altamente ritualizado. En él vienen a unirse la ceremonia del poder y la forma de la experiencia, el despliegue de la fuerza y el establecimiento de la verdad. En el corazón de los procedimientos de disciplina, manifiesta el sometimiento de aquellos que se persiguen como objetos y la objetivación de aquellos que están sometidos. La superposición de las relaciones de poder y de las relaciones de saber adquiere en el examen toda su notoriedad visible².

Efectivamente, el examen otorga al alumno/a una calificación, expresión matemática de los saberes, pasando a ocupar un lugar jerárquico entre sus iguales a

Foucault, M.: Vigilar y castigar, México, Siglo xxi, 1976, p. 189. 
¿FORMACIÓN/DEFORMACIÓN DEL MAESTRO?

REFLEXIONES Y LAMENTOS DE DOS PROFESORES INCRÉDULOS

ALEJANDRO ÁVILA FERNÁNDEZ Y JUAN A. HOLGADO BARROSO

partir del cual es valorado y juzgado. De igual forma sanciona con base en la no superación de un listón determinado, pero además es el elemento práctico que establece la distancia simbólica entre el profesor y el alumno y, desde otra perspectiva, individualiza, impidiendo cualquier posibilidad de trabajo colectivo. Aunque todos los exámenes cumplen la misma función, existirán distintas modalidades según el momento de aplicación y lo que intentan medir o valorar, propias de un esquema de control similar al establecido desde la creación de nuestras instituciones, independientemente de la diversidad terminológica.

En principio, el instrumento para el acceso a la enseñanza será el examen de ingreso, suponiendo un reconocimiento del nivel instructivo necesario para comenzar los estudios e incluso se puede considerar como introductor en el ritual examinador. Otras pruebas estarán destinadas a comprobar el grado de adquisición de los saberes impartidos por los profesores, medio más directo e inmediato de evaluación a lo largo de la formación. Y, por último, las pruebas finales como último y definitivo acto sancionador y autentificador para el ejercicio del magisterio. Por lo tanto, se dotarán de unas medidas institucionales, simbólicas y ceremoniales acordes con su finalidad: establecimiento de tribunales, delimitación temporal y fijación de ejercicios a superar.

Otro componente a destacar sería el manual o libro de texto, instrumento fundamental en el desarrollo tradicional de las disciplinas escolares. La evolución de los sistemas educativos nos lo muestra como el medio por excelencia para la adquisición de los contenidos curriculares, siendo la base de la propia actuación docente, limitada -en la mayoría de los casos- a reproducir/transmitir los saberes reflejados en sus páginas y elaborados fuera de la institución.

Así, la institución educativa será un mero agente transmisor de un conjunto de conocimientos elaborados fuera de la misma. De forma genérica, se define como un cuerpo de conocimientos derivado de una reconstrucción social del mundo exterior, provisto de una lógica interna y articulado en torno a temas específicos. Su mayor o menor preponderancia en la enseñanza responde a los principios y valores -manifiestos o latentes-inmersos en la formación del individuo y al mismo tiempo refleja la manera de concebir la propia disciplina y su lugar en el currículum. Sus conocimientos, función social y valores se justifican a través de la presentación, organización y jerarquización de los contenidos que, a su vez, responden a las concepciones científicas y metodológicas de cada contexto histórico-educativo. Su protagonismo en la formación de los sujetos y de los maestros en particular no puede ser analizado sin contar con una visión amplia del fenómeno, donde se integran e interrelacionan factores e intereses tanto en el ámbito interno como en el externo del proceso educativo. Por lo tanto, nos parece oportuno partir de la concepción completa y crítica aportada por Apple:

Los libros de texto no son simplemente «sistemas de transmisión» de «datos». Son, a un tiempo, resultado de actividades, conflictos y compromisos políticos, económicos y culturales. Están concebidos, diseñados y escritos por personas reales con intereses reales. Se publican en función de las limitaciones políticas y económicas de los mercados, los recursos y el poder... A través de su contenido y de su forma destacan construcciones de la realidad, formas particulares de seleccionar y organizar el vasto universo de los posibles conocimientos. Acogen la tradición 
¿FORMACIÓN/DEFORMACIÓN DEL MAESTRO?

REFLEXIONES Y LAMENTOS DE DOS PROFESORES INCRÉDULOS

ALEJANDRO ÁVILA FERNÁNDEZ Y JUAN A. HOLGADO BARROSO

selectiva: la selección de alguien, la visión del conocimiento y de la cultura legítimos de alguien, una visión que, al conceder derechos al capital de un grupo cultural, los retira al capital de los otros. También son mercancías económicas. Aunque pueden ser el vehículo de las ideas, no por ello dejan de ser mercancías que hay que «distribuir en el mercado»3.

Dentro de la enseñanza normalista, tanto en la evolución de sus contenidos como de sus formas, se pondrán de manifiesto unas construcciones particulares de la realidad, derivadas de formas concretas de seleccionar y organizar el extenso universo de los posibles conocimientos que deben integrar la capacitación inicial del magisterio.

En estrecha relación con lo dicho hasta aquí podemos situar nuestro tercer pilar para el análisis del fenómeno educativo normalista, el componente legislativo, un enfoque novedoso en lo que supone el estudio y la evolución de la capacitación del maestro. Aquí es donde situamos el concepto foucaultiano de gubernamentalidad, entendido como el conjunto de instituciones, procedimientos, análisis y reflexiones, cálculos y tácticas que han permitido ejercer al Estado una forma específica y muy compleja de poder, y más concretamente la legislación normalista se convierte a la vez en un instrumento y en un procedimiento regulador del poder y control sobre la formación del Maestro. Las acciones legislativas existen en relación con decisiones de poder de los respectivos gobiernos, que influyen sobre la práctica y la formulación de la política educativa.

Desde una visión histórica española, Luzuriaga hizo notar que existen leyes que no se cumplen nunca y otras que se cumplen en forma distinta a como fueron promulgadas. En este sentido existe, sobre todo en los pueblos latinos, una tendencia a legislar sin tener en cuenta las condiciones de la realidad, y de aquí muchas veces su incumplimiento. Esto no obstante, la legislación puede servir para el conocimiento de la política pedagógica de un país y de la orientación de su educación. En este sentido, la legislación viene a ocupar un lugar intermedio entre las teorías pedagógicas y políticas y la realidad social y educativa de un país determinado. Mientras que en los latinos predomina en general la precipitación y la improvisación, en los anglosajones se legisla más moderadamente y con mayor preparación. En éstos, por lo general, la promulgación de las leyes va precedida de prolijos informes y estudios a cargo de técnicos y especialistas. En los latinos, por el contrario, todo se confía a la discusión pública sin grandes estudios previos por los parlamentarios, que en general no tienen una preparación adecuada para ello y, por decirlo de forma más castiza, ni la más remota idea. De aquí la frecuencia aterradora de las reformas de la educación pública en esos países, incluimos España claro está, y la ineficacia de sus leyes escolares.

De manera general, en los mecanismos cambiantes de regulación en la formación del profesorado se distinguen los actores y las prácticas discursivas. Desde los primeros se pueden distinguir la formulación de las políticas, donde se encuentra el gobierno como poder legislativo y ejecutivo, elabora la ley o norma y la ejecuta en los distintos ámbitos de la formación del magisterio, las agencias de

Apple, M. W.: «El libro de texto y la política cultural», Revista de Educación, n. ${ }^{\circ}$ 30I (1993), pp. IIO y II4. 
habilitación o certificación, las prácticas de evaluación, las diferentes administraciones periféricas al Estado, las fundaciones y los grupos profesionales, mientras que en la ejecución de las políticas estarían los grupos de investigación, los grupos profesionales, las universidades, los sindicatos docentes, los ministerios, las consejerías o departamentos de educación. En el plano de las prácticas se recogen las declaraciones, dictámenes y opiniones políticas, las medidas, orientaciones y normas administrativas y estadísticas, las categorías de investigación y las diferencias y distinciones que forman el «sentido común» de la enseñanza/escolarización. Por ello, las prácticas discursivas aplicadas a nuestro estudio serían el conjunto de normas, reglas o leyes históricas y actuales, determinadas en el espacio y el tiempo por las diferentes políticas educativas, que rigen lo que se debe hacer y lo que no se debe hacer en la formación del maestro/a, identificando en todo momento quién dicta la disposición, quién debe ejecutarla y quién debe sufrirla.

Las prácticas discursivas cobran aquí sentido porque las leyes están incorporadas en los procesos técnicos, las instituciones normalistas, las pautas de comportamiento de los actores, en las formas de transmisión y difusión y en formas pedagógicas que, al mismo tiempo, las imponen y las mantienen.

La ley es la sanción normalizadora destinada a la capacitación del maestro/a, en el futuro agente disciplinario de sus alumnos/as de enseñanza primaria, que lleva consigo una manera específica de castigar. El orden que los castigos disciplinarios deben hacer respetar es de índole mixta: es un orden «artificial», dispuesto de manera explícita por una ley, un programa, un reglamento, pero es también un orden definido por unos procesos naturales y observables: la duración de un aprendizaje, el tiempo de un ejercicio, el nivel de aptitud se refieren a una regularidad, que es también una regla. La distinción y la distribución de la normativa según los rangos o los grados tienen un doble papel: señalar las desviaciones, jerarquizar las cualidades, las competencias y las aptitudes; pero también castigar y recompensar. Funcionamiento penal de la ordenación y carácter ordinal de la sanción.

Foucault nos advierte que el arte de castigar utiliza cinco operaciones distintas: primera, referir los actos, los hechos extraordinarios, las conductas similares a un conjunto que es a la vez campo de comparación, espacio de diferenciación y principio de una regla a seguir; en segundo lugar, medir en términos cuantitativos y jerarquizar en términos de valor las capacidades, el nivel, la «naturaleza» de los individuos. Hacer que juegue, a través de esta medida «valorizante», la coacción de una conformidad que realizar. En fin, trazar el límite que habrá de definir la diferencia respecto de todas las diferencias, la frontera exterior de lo anormal. La penalidad perfecta que atraviesa todos los puntos y controla todos los instantes de las instituciones disciplinarias, compara, diferencia, jerarquiza, homogeneiza, excluye. En una palabra, normaliza.

Precisamente esa es la finalidad de la institucionalización de la capacitación del maestro, la creación de las Escuelas Normales, el poder de la norma. Lo «normal» se establece como principio de coerción en la enseñanza con la instauración de una educación estandarizada y el establecimiento de las Escuelas Normales. Se tiende a sustituir o al menos a agregar a las marcas que traducían estatutos, privilegios (por ejemplo, los concedidos a los gremios de maestros), todo un juego de grados de normalidad, que son signos de adscripción a un cuerpo social 
¿FORMACIÓN/DEFORMACIÓN DEL MAESTRO?

REFLEXIONES Y LAMENTOS DE DOS PROFESORES INCRÉDULOS

ALEJANDRO ÁVILA FERNÁNDEZ Y JUAN A. HOLGADO BARROSO

homogéneo, el magisterio primario, pero que tienen en sí mismos un papel de clasificación, de jerarquización y de distribución de los rangos. En un sentido, el poder de normalización obliga a la homogeneidad; pero individualiza al permitir las desviaciones, determinar los niveles, fijar las especialidades y hacer útiles las diferencias ajustando unas a otras. Se comprende que el poder de la norma funcione fácilmente en el interior de un sistema de igualdad formal, ya que en el interior de una homogeneidad que es la regla, introduce, como un imperativo útil y el resultado de una medida, todo el desvanecido de las diferencias individuales.

En este proceso y/o espacio micropolítico -que así se llama ya que se ubica en una parcela pequeña, inmediata, y firme de poder, de control, en donde se llevan a cabo actividades relativamente fáciles de manejar-, se produce, de forma general, lo que se ha dado en llamar «las incertidumbres estructurales», como así las llamara Foucault; es decir, todo aquello que, aun dentro de la programación, se desvela y se revela por actitudes que son o pueden ser de cierto autoritarismo, y provenientes, la mayor parte de ellas, de la jerarquía, lo cual conduce a estados de conflicto, que en un momento pueden ser aislados y no trascender y, en otros, pueden bloquear la vida habitual del discurrir académico y provocar, como de hecho sucedió y aún sucede, enfrentamientos que no llevan a nada más que a un estancamiento y/o retroceso de los saberes y del progreso educativo. Los poderes fácticos han cometido y cometen gravísimos errores en la formación del magisterio, en su posición de autocracia a modo de liderazgo -entendido como un acto de dominio o afirmación de la responsabilidad suprema, de carácter autoritario o patriarcal-, con el establecimiento de normas inviolables, consideradas sagradas, por lo que todo síntoma o manifestación de oposición es contemplado como un signo de ruptura del proceso político normal y por extensión de cualquier acción educativa.

Cuando se abre el debate social, si alguna vez se ha abierto de veras, acerca de la calidad de la enseñanza -puede citarse la creación de la Escuela de Estudios Superiores del Magisterio en I909 o el Plan Profesional de la Segunda República decreto orgánico de 1931, reglamento de 1933-, nunca se cita, o como mucho tímidamente, que uno de los obstáculos definitivos para conseguir una más alta calidad es haber convertido a los maestros/as en administrativos y a los equipos directivos de los colegios, de las escuelas, de los centros de enseñanza en suma, en jefes de negociado.

Es esto algo más que un ejemplo, es la más pura realidad. La formación del magisterio español es, desde antaño, la historia de una decepción, entendiendo por decepción, engaño, desilusión, chasco; o sea, el resultado evidentemente contrario, negativo, de lo que se debe recibir o al menos está programado como posible en un orden positivo de cosas. Las leyes y teorías educativas han ido incorporando temas irrelevantes a los distintos planes de estudios y eliminando contenidos importantes que formaban parte de ellos, invocando la necesidad de aquellas doctrinas conceptuales como algo realmente ineludible, al menos por lo que a simple vista parecían; al fin y al cabo en la mente del legislador se mantenía, se mantiene, la idea de que esos temas eran, son, irrelevantes, pero a la vez menos comprometedores, lo que a simple vista no lo parecía para el estudiante, para el futuro maestro. 
Esta cuestión así planteada no provoca la menor inquietud; sólo aparece el fantasma de la duda cuando vives los conocimientos que se están impartiendo, a la vez que necesitas respuestas ante los problemas educativos de alcance inmediato en tu entorno y no son evidenciados ni tratados en la dinámica académica, y es entonces cuando empiezas a echar de menos cosas que deberían contemplarse en el plan de estudios y, sin embargo, brillan por su ausencia; con lo cual eres consciente de que no habría mucha diferencia entre acudir a un centro escolar, a una Facultad de Educación o comprarse unos fascículos en cualquier kiosco, porque el nivel de contenido, diría divulgativo, intrascendente, es muy similar.

Los planes de estudio en la formación de los maestros y maestras, aunque esto podría ser extensivo al resto de las carreras universitarias, han copiado el modelo de los medios de comunicación que pueden ofrecer una noticia insignificante como si tuviera una enorme importancia y viceversa. La grandilocuencia del nombre de una asignatura parece ofrecernos el «oro y el moro» al final nos está induciendo a un estudio de algo muy superficial. Así pues, la labor primordial de los centros de enseñanza en la formación de maestros y maestras, además de esta formación, es, debería ser, desarrollar en los alumnos un criterio que les permita discernir entre los contenidos necesarios y valiosos y los meramente anecdóticos, con ello se eliminarían temas y conocimientos que son los que han estado presentes desde el origen de nuestra civilización, y que de llevarse a cabo por meras decisiones político-coyunturales afectarían a todo el entramado de nuestra cultura desde sus propios cimientos.

Y ahora que estamos padeciendo la implantación del Espacio Europeo, de esta Europa de las competencias educativas, dejando atrás la pedagogía de los objetivos nacida en los años setenta y crecida hasta hace poco tiempo, donde se vinieron a demostrar sus limitaciones y fracasos y muy particularmente en la formación de los maestros, la Universidad será el nivel donde se experimente a modo de conejillo de Indias ese paradigma para la capacitación que responde a un discurso político e ideológico del pensamiento neoliberal que quiere cambiar radicalmente el sentido o función de la enseñanza superior y, en nuestro caso, de la profesionalidad docente.

Martínez Bonafé, desde una perspectiva discursiva, afirma que se pretende imponer un proyecto hegemónico de coherencia institucional bajo un lenguaje cargado de poder simbólico y de acción política, pues tras la aparente neutralidad y debate técnico sobre cuestiones puntuales de la reforma y el abandono de las grandes narraciones, se instala una nueva lógica esencialista: el saber adquirido en la universidad debe estar vinculado directamente con el trabajo y el consumo, dos características esenciales del modelo económico neoliberal con una clara intención colonizadora hacia el conjunto de la vida socialt.

Es, en definitiva, un intento de implantar un nuevo modelo de universidad, que pasaría del humanista, que tiene su tradición en el movimiento ilustrado, a otro económico y de mercado, más preocupado por la inserción laboral y los intereses económicos que en la formación integral y crítica de los estudiantes. Lo

4 Martínez Bonafé, J.: «La formación del Profesorado y el discurso de las competencias», Revista Interuniversitaria de Formación del Profesorado, vol. I8 (3) (2004), pp. I27-I43. 
¿FORMACIÓN/DEFORMACIÓN DEL MAESTRO?

REFLEXIONES Y LAMENTOS DE DOS PROFESORES INCRÉDULOS

ALEJANDRO ÁVILA FERNÁNDEZ Y JUAN A. HOLGADO BARROSO

que está en cuestión es saber si la universidad es una instancia formativa especializada y estrechamente vinculada y adaptada a las necesidades inmediatas de las empresas, o si, por el contrario, tiene como finalidad el conseguir una formación general que permita a los estudiantes una mayor autonomía en sus vidas.

Es por todo ello que echamos en falta un modelo más reflexivo y crítico, capaz de formar a profesionales reconocidos y comprometidos con el cambio de su realidad escolar y social, colaborativos e innovadores. Rechazamos la burocratización dentro de nuestra profesión de enseñantes, ya que ésta es sólo una medida de control de tal forma que a nuestros gobernantes lo que más les interesa es desplazar la realidad, que los escritos, los comunicados, los papeles en definitiva enturbien y distraigan nuestra verdadera función profesional. Pero lo importante es que la reforma se cumpla, es así como el político se encuentra tranquilo, relajado.

Echamos de menos unos planes de estudios acordes con una racionalidad práctica y crítica, referentes de una capacitación acorde con el papel del maestro en una escuela y en una sociedad complejas:

[...] los planes de estudio no tienen por qué unificarse, deben construirse como estrategias de formación, es decir como planes de acción flexibles, pensados para incorporar permanentemente los aprendizajes que de su contacto con la realidad profesional se deriven. Planes inmersos en las situaciones profesionales reales con su imprevisibilidad, particularismo, indeterminación, carácter holístico, saberes tácitos, dimensiones emocionales... Planes que, por esto mismo, no tienen por qué estar estandarizados más allá de su común carácter de flexibilidad y su vinculación con la autoevaluación y heteroevaluación participativa, su evaluación y transformación permanente para responder cada vez mejor a las necesidades sociales de carácter local y dimensión globals.

Echamos de menos una propuesta unificada de formación del profesorado de los diferentes niveles. Se ha perdido una oportunidad de oro. Se mantiene un modelo de formación dual: por un lado, la formación de los docentes de educación infantil y primaria y, por otro, los de secundaria. Hubiera sido necesaria además una reforma de segundo orden

en nombre de una actuación coherente a lo largo de la escolaridad obligatoria, y de la superación de esa brecha entre culturas e identidades profesionales que tan flaco favor le ha hecho a la causa -ya bastante ardua- de la comprehensividad, se podía haber pensado, quizá, en un grado común para todo el profesorado del tronco obligatorio, con líneas de especialización prolongadas mediante postgrados. No ha sido así ${ }^{6}$.

Echamos en falta, por decir algo más o menos definitivo, pero sustancialmente no definido, una reforma de abajo hacia arriba, con una mayor implicación de los

Cascante Fernández, C.: «La reforma de los Planes de Estudio. Un análisis político de los discursos sobre la Formación Inicial de los Profesionales de la Educación», Revista Interuniversitaria de Formación del Profesorado, vol. I8 (3) (2004), p. I64.

6 Romero, J. y Luis Gómez, A.: «¿Sujetos agentes o pacientes de la anunciada "sociedad del conocimiento"? Las actuales políticas de formación inicial del profesorado y la redefinición en curso de la profesionalidad docente», Con-ciencia Social, n. ${ }^{\circ}$ Io (2006), p. 36. 
agentes educativos, de trabajo y propuestas desde la base, desde el profesorado y el alumnado universitarios, desde el magisterio en ejercicio, desde otras instancias y movimientos de renovación pedagógica, desde sectores que vienen trabajando años atrás en una alternativa a la formación del profesorado en general:

[...] es posible que lo del EEes resulte inevitable, pero lo que hace falta es que resulte ilusionante. De otro modo, todo quedará en mera reforma normativa impuesta verticalmente e implementada de manera técnica y burocrática, en vez de en una auténtica innovación educativa, adoptada y compartida horizontalmente e implementada conforme a una racionalidad práctica (personal y deliberativa) y crítica (colaborativa y transformadora de las condiciones institucionales y estructurales de la Universidad) ${ }^{7}$.

Echamos en falta, en definitiva, un cambio social acorde con las necesidades y los problemas sociales. A la postre, sin estas medidas, la educación se convierte en un mercado en el que compiten quienes más medios y recursos poseen con aquellos que tienen menos o incluso carecen de ellos, contando además los primeros con la inhibición o el apoyo de unos poderes públicos que configuran dicho sistema en función de sus intereses y necesidades.

Echamos en falta, y más aún por lo que nos toca, una reforma desde la perspectiva histórica, como bien dice el profesor Viñao $\mathrm{Frago}^{8}$, ya que los reformadores carecen de esta perspectiva histórica, siendo su mal el presentismo, especialmente por la idea de la creencia mesiánica de que se parte de cero y de que todo puede ser modificado y se modificará a corto plazo desde el mismo momento que pasando por encima de la opinión pública todo se refleje en el Boletín Oficial del Estado y [...] punto.

No hay que dejar de mirar atrás, es decir, no debemos atentar contra la memoria tampoco en estas lides. Insto no sólo a la mirada crítica y denunciante que exige la construcción de nuestra historia más reciente, también me refiero a aquella que nos ha dotado de las raíces educativas, desde la misma existencia de los sistemas educativos a partir del siglo xIx. Se nos convoca de un modo interesado y esnob al olvido de culturas escolares que fueron y son germen y caldo de cultivo, a hacer añicos aquel proyecto emancipador, generador de conciencias autónomas que, al menos como promesa, podría alumbrar una resistencia. Pretenden hacernos creer que somos homologables como los productos en serie, que la educación es mercancía intercambiable en un mercado de libre competencia. Hay un sospechoso intento por sepultar tradiciones magisteriales, transmitidas a través del sabio hacer de una profesión dignamente llevada, por entenderlas ya inválidas... o peligrosas (no olvidemos, que en la tradición puede estar la fuente del invento). Convencernos de que en el fondo debemos ser y estar concebidos como una réplica a antojo de los gobernantes, del analfabetismo de los gobernantes; y si no pueden convencernos

Trillo Alonso, F.: «Otra vuelta de tuerca a eso del Espacio Europeo de Educación Superior», ponencia presentada en las Jornadas sobre Grados y Postgrados en el EEES, organizadas por el Decanato de la Facultad de Educación de la UNED, 2006.

8 ViñaO Frago, A.: «El éxito o fracaso de las reformas educativas: condicionantes, limitaciones, posibilidades», en GIMENO SACRISTÁN, J. (comp.): La reforma necesaria: entre la política educativa y la práctica escolar, Madrid, Morata, 2006, pp. 43-60. 
¿FORMACIÓN/DEFORMACIÓN DEL MAESTRO?

REFLEXIONES Y LAMENTOS DE DOS PROFESORES INCRÉDULOS

ALEJANDRO ÁVILA FERNÁNDEZ Y JUAN A. HOLGADO BARROSO

de que, al menos, a fuer del agotamiento de una lucha secular estéril, acabemos claudicando.

Lamento el tono de estas reflexiones, pero la realidad no puede seguir maquillándose ni escondiéndose, es demasiado lo que está en juego. En la formación del magisterio en España, tanto en el pasado como en el presente, han quedado bien patentes y asentados los modelos de control, los modelos de discurso, las tensiones, las ambigüedades, las luchas, etc., que son nuestro mejor instrumento para conocer toda su trayectoria ¿formadora o deformadora? Sirva esta aportación como nota para una reflexión sobre el presente y para abrir un debate constructivo para el futuro.

\section{Bibliografía}

Álvarez-Uría, F.: «Microfísica de la escuela», Cuadernos de Pedagogía, 203 (1992), pp. 55-59. Ávila Fernández, A.: La Escuela Normal de Maestros de Sevilla en la segunda mitad del siglo XIX, Sevilla, Alfar, 1986a.

Ávila Fernández, A.: Las Escuelas Normales españolas durante el siglo XIX. Disposiciones legislativas y libros de texto, Sevilla, Universidad, 1986b.

Ávila Fernández, A. y Holgado Barroso, J.: «Poder y control en la vida académica normalista. Micropolítica en la formación del magisterio sevillano», en XI Coloquio Nacional de Historia de la Educación: La acreditación de saberes y competencias. Perspectiva histórica, Oviedo, Universidad de Oviedo/Sociedad Española de Historia de la Educación, 200I, pp. 555-566.

Ávila Fernández, A. y Holgado Barroso, J.: Formación del magisterio en España. La legislación normalista como instrumento de poder y control (I834-2007), Madrid, Ministerio de Educación, Política Social y Deporte (MEPSYD), 2008.

Ball, S. J.: La micropolítica de la escuela. Hacia un teoría de la organización escolar, Barcelona, Paidós, 1989 .

Ball, S. J. (comp.): Foucault y la educación. Disciplinas y saber, Madrid, Morata, 1997.

BRICALL, J. M.: Universidad 2000, Madrid, CRUE, 2000.

Castel, R.; Donzelot, J.; Foucault, M.; Gaudemar, J.-P. De; Grignon, C. y Muel, F.: Espacios de poder, Madrid, La Piqueta, I99I.

Cuesta Fernández, R.: Felices y escolarizados. Crítica de la escuela en la era del capitalismo, Barcelona, Octaedro-EUB, 2005.

Escudero, J. M. y Luis Gómez, A.: La formación del profesorado y la mejora de la educación. Políticas y prácticas, Barcelona, Octaedro, 2006.

Foucault, M.: Vigilar y castigar, México, Siglo XXI, 1976.

Foucault, M.: Microfísica del poder, Madrid, La Piqueta, 1992.

García Calvo, A.: "Aguantando y aguantando», Archipiélago. Cuadernos de Crítica de la Cultura, n. ${ }^{\circ} 6$ (199I), pp. 37-4I.

Giroux, H. A.: Los profesores como intelectuales. Hacia una pedagogía crítica del aprendizaje, Barcelona, Paidós, 1997.

Holgado Barroso, J.: Las Escuelas Normales de Sevilla durante el siglo XX. Tradición y renovación en la formación del magisterio primario, Sevilla, Universidad, 2000.

Lerena Alesón, C.: Escuela, ideología y clases sociales en España, Barcelona, Ariel, 1976.

LeRena Alesón, C.: Reprimir y liberar. Crítica sociológica de la educación y de la cultura contemporáneas, Madrid, Akal, 1983.

Lozano Seijas, C.: La educación en los siglos XIX y XX, Madrid, Síntesis, I994. 
Macías Picavea, R.: El problema nacional. Hechos, causas, remedios, Madrid, Librería General de Victoriano Suárez, I899.

Melcón Beltrán, J.: La formación del profesorado en España (I837-I9I4), Madrid, Ministerio de Educación y Ciencia, 1992.

Ortega, F.: «La configuración histórica de la profesión de maestro en España (Algunos factores determinantes)», Studia Paedagogica, n. ${ }^{\circ}$ I9 (I987a), pp. II-29.

Ortega, F.: «Un pasado sin gloria. La profesión del maestro (la formación de los maestros en España)», Revista de Educación, n. ${ }^{2} 84$ (1987b), pp. 19-38.

Popkewitz, T. S. (comp.): Modelos de poder y regulación social en Pedagogía. Crítica comparada de las reformas contemporáneas de la formación del profesorado, Barcelona, Pomares-Corredor, 1994 .

Romero Morante, J. y Luis Gómez, A.: La formación del profesorado a la luz de una "profesionalización democrática», Santander, Consejería de Educación de Cantabria, 2007.

TuRIN, I.: La educación y la escuela en España de 1874 a 1902, Madrid, Aguilar, 1967.

VARELA, J. y ORTEGA, F.: El aprendiz de maestro, Madrid, MEc, 1985.

ZufiaurRe, B.: ¿Se puede cambiar la educación sin contar con el profesorado? Reflexiones sobre treinta y seis años de cambios en España: 1970-2006, Barcelona, Octaedro, 2007. 